\title{
Kahramanmaraş’ta Kentleşme ve Yeşil Alan Varlığındaki Zamansal Değişimlerin İncelenmesi
}

\author{
Hakan DOYGUN ${ }^{1 *}$, Mustafa ATMACA ${ }^{2}$, Murat ZENGiN ${ }^{3}$ \\ ${ }^{1}$ KSÜ, Orman Fakültesi, Peyzaj Mimarlığı Bölümü, Kahramanmaraş \\ ${ }^{2}$ MKÜ, Mimarlık ve Tasarım Fakültesi Peyzaj Mimarlığı Bölümü, Antakya \\ ${ }^{3}$ Pamukkale Üniversitesi, Mimarlık ve Tasarım Fakültesi, Peyzaj Mimarlığı Bölümü, Denizli
}

Geliş (Received): 15.12.2014

Kabul (Accepted): 03.12.2015

ÖZET: Kahramanmaraş kenti için gerçekleştirilen bu çalışma ile kentsel alan kullanım yapısında 2000, 2006 ve 2012 yıllarında meydana gelen değişimler ve bu değişimlerin yeşil alan varlığı üzerindeki etkileri incelenmiştir. Yüksek çözünürlüklü uydu görüntüleri ve coğrafi bilgi sistemleri yardımıyla gerçekleştirilen analizlerde, araştırma alanının \%25'ini meydana getiren 25372 da arazide alan kullanımlarının değişime uğradığı belirlenmiştir. Aktif yeşil alan yüzölçümü 12 yıl boyunca dört kat artmış, ancak bu yöndeki iyileşmenin kişi başına metrekare oranı, yeşil alanlara yürüyerek ulaşma olanağı, ortalama parsel genişliği ve yeşil alanların araştırma alanı bütünü içerisindeki oranına yeterince yansımadığı anlaşılmıştır. Kentsel yeşil alan yeterliğinin ideal düzeye ulaştırılabilmesi için, yeşil alanların daha fazla miktarda, geniş parseller halinde ve kent geneline homojen dağılmış bir şekilde planlanması ve bu bakış açısının nazım ve uygulama imar planlarına da yansıtılması gerekmektedir.

Anahtar Kelimeler: Kentsel yeşil alanlar, Coğrafi Bilgi Sistemleri, Zamansal değişim, Kahramanmaraş

\section{Analysing Temporal Changes in Urbanization and Green Areas in Kahramanmaraş}

ABSTRACT: Within this research realized in the city of Kahramanmaraş, areal changes for urban land use types occurred in 2000, 2006 and 2012, and the effects of these changes on the green areas have been analyzed. During the analyses realized by using high resolution satellite images and geographical information systems, it is concluded that land use types have been changed in 25372 decare which generates $25 \%$ of the study area. Areal coverage of the active green spaces has been increased four times during 12 years, but this improvement has not affected positively the rate of square meter per person, opportunity for access by walking, mean surface area of the parcels, and the rate in the whole urban area of the green areas. For improving ideally the urban green area sufficiency in the city, a great deal of green areas should be established, the parcels should be planned large and distributed homogeneously throughout the city, and these approaches should be adapted to urban development plans.

Key Words: Urban green spaces, Geographical Information Systems, Temporal change, Kahramanmaraş

\section{GİRIŞ}

Kentler giderek artan bir şekilde yapılaşma, yanlış arazi kullanımları, biyoçeşitlilik kayıpları, iklim değişikliği, su, hava ve gürültü kirliliği gibi yaşam kalitesini olumsuz yönde etkileyen çevre sorunlarına maruz kalmaktadirlar (Westmacott 1991; Doygun ve ark. 2010). Kent yaşantısının insanlar ve doğal yaşam bakımından sürdürülemez hale gelmesine neden olan bu sürecin yavaşlatılması veya durdurulması, çevre koşullarının iyileştirilmesine yönelik önlemler alınmasını gerektirmiştir. $\mathrm{Bu}$ anlamda yeşil alanlar, kentleşmenin insanlar ve doğal yaşam üzerindeki olumsuz etkilerinin azaltılması bakımından başvurulan en etkili planlama araçlarından olmuşlardır (Shin ve Lee, 2005; Ülger ve Önder, 2006; Uy ve Nakagoshi, 2008; Wolch ve ark., 2014). Arazi kullanımlarını sınırlama ve yönlendirme (Li ve ark., 2005), bitki ve yaban hayatı türleri için korunma ve yaşama alanları oluşturma (Attwell, 2000; Eşbah, 2006), çevre kirliliği ve 1S1 adas1 etkilerini azaltma (Yıldizc1, 1982; Solecki ve ark., 2005), kent mikro klimasını düzenleme (Shin ve Lee, 2005) özellikleri yönünden kentsel ekosistemlerin en önemli bileşenlerindendir. Aynı zamanda yeşil alanlar kent estetiğini iyileştirme, kent aidiyetini güçlendirme, rekreasyon olanakları sunma, kent halkının sosyal hayata entegrasyonunu kolaylaştırma, insan ve doğa arasındaki ilişkiyi sağlama (Gül ve Küçük, 2001; Grahn ve Stigsdotter, 2003; Manlun, 2003; Ridder ve ark., 2004; Littke, 2015) gibi özellikleriyle de kent yaşantısını insanlar lehine psikolojik ve sosyolojik bakımdan iyileştirerek düzenleyen kent ögeleridir. $\mathrm{Bu}$ yönleriyle yeşil alanların, kent yaşantısında konut ihtiyacı kadar büyük bir öneme sahip olduğunu söylemek mümkündür. Nitekim Belçika'nın Leuven kentinde yapılan bir araştırma (Tratsaert, 1998), kamusal yeşil alan ve çocuk bahçesinden yoksun olması nedeniyle şehir merkezini terk eden halkın, kentin daha fazla yeşil dokuya sahip dış kesimlerinde yerleşim alanı bulma arayışına girdiğini ortaya koymaktadır (Herzele ve Wiedemann, 2003).

Kentler, hızlı nüfus artışı nedeniyle başta konut ihtiyacı olmak üzere nüfusun giderek artan arazi taleplerini karşılamak amacıyla hızlı büyüme eğilimine girmektedirler. Söz konusu büyüme eğilimi çerçevesinde ise kentsel yeşil alanların nitelik ve nicelik yönünden yeterliğine gereken önem verilmemekte, öncelikle konut açığının giderilmesi amaçlanan kent

*Sorumlu yazar: Doygun, H., doygun @ksu.edu.tr 
planlama çalışmaları kapsamında (Altunkasa ve Uslu, 2004) konutlardan arta kalan parsellerin yeşil alan olarak değerlendirilmesi yoluna gidilmektedir. $\mathrm{Bu}$ durum, zayıf fonksiyonlara sahip biçimde planlanan yeşil alanların aynı zamanda kent genelinde homojen olmayan bir dağılım sergilemesine ve kent halkının da yeşil alanlardan eşit bir şekilde yararlanamamasına neden olmaktadır (Doygun ve İlter, 2007).

Kahramanmaraş kenti örneğinde gerçekleştirilen bu çalışmada yapılaşma alanları, yeşil alanlar ve kent nüfusunda yıllar bazında ortaya çıkan değişimlerin yeşil alan yeterliği üzerine etkileri uzaktan algılama verileri ve coğrafi bilgi sistemleri yardımıyla incelenmiş, böylece kent halkının yeşil alanlardan yararlanma olanakları üzerine değerlendirmeler yapılmasına olanak sağlanmıştır. Yeşil alan yeterliği salt kişi başına metrekare oranlarına bağlı kalınmayarak; yeşil alanlara yürüyerek ulaşma olanağı, ortalama parsel genişliği ve yeşil alanların araştırma alanı bütünü içerisindeki oranı gibi çok yönlü bakış açısı ile incelenmiş, elde edilen verilerden yola çıkılarak yeşil alanların kent halkına yönelik yararlarını artırmayı amaçlayan öneriler geliştirilmiştir.

\section{MATERYAL ve METOT}

Araştırma, Türkiye'nin Doğu Akdeniz Bölgesi'nde yer alan Kahramanmaraş kentinde belediye sınırları içerisinde yürütülmüştür. Kuzeyde Ahir Dağı, güney ve doğu kesimlerinde Kahramanmaraş Ovası arazileri ve batıda Sır Baraj Gölü ile çevrelenen araştırma alanı 10.333 ha genişliğe sahiptir (Şekil 1). Yer verilerinin derlenmesinde 2000 ve 2012 tarih aralığındaki uydu görüntülerinden yararlanılması nedeniyle, araştırma alanının belirlenmesinde o dönemdeki belediye sınırları göz önüne alınmıştır.

Yapılaşma alanları ve yeşil alanlarda zaman içerisinde meydana gelen değişimlerin incelenmesi üzerine kurgulanan çalışmaya ait akış diyagramı Şekil 2 'de verilmiş, kullanılan materyal ve yönteme ait bilgiler aşağıda aktarılmıştır.

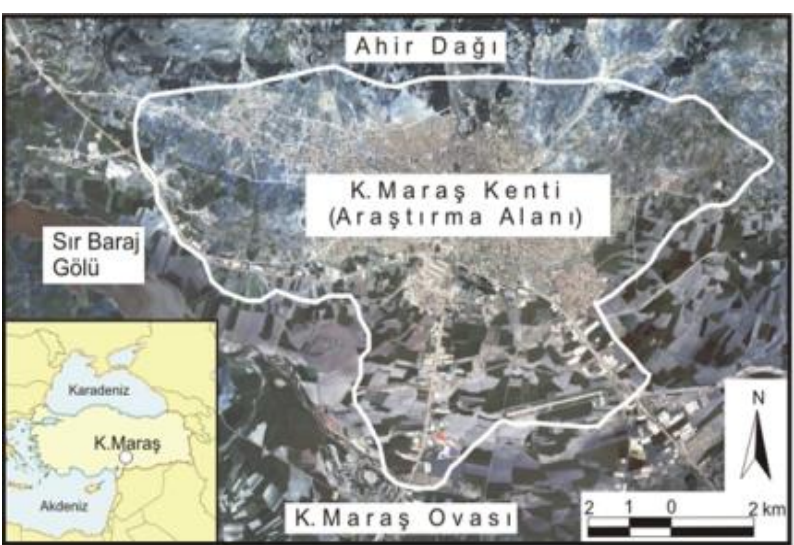

Şekil 1. Araştırma alanı coğrafi konumu

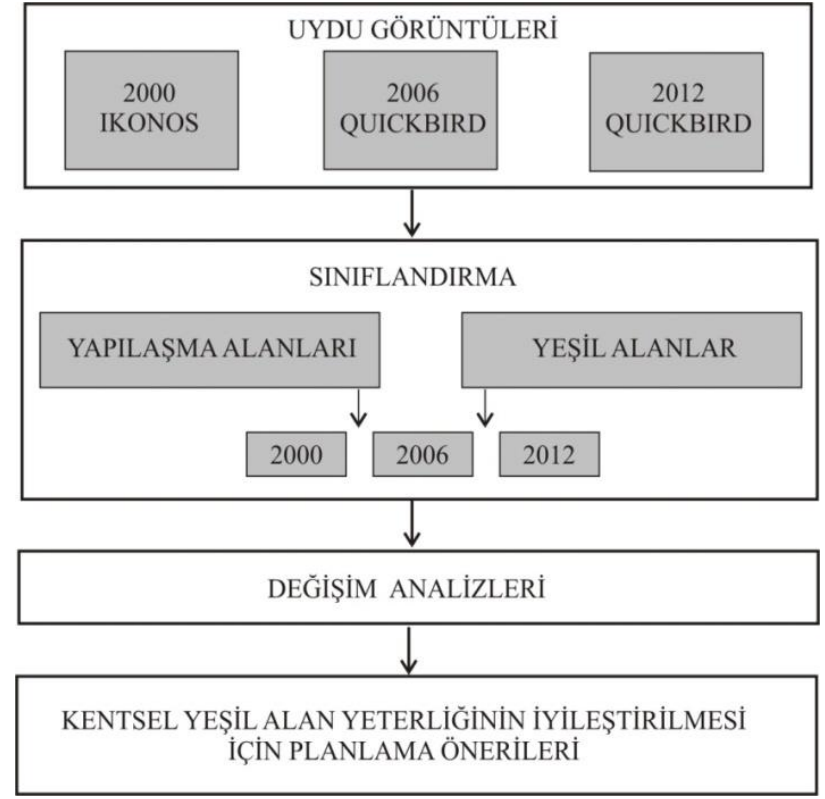

Şekil 2. Çalışma akış diyagramı

\section{Veri seti ve sayısallaştırma}

Kahramanmaraş kentine ait yer verilerinin derlenmesinde üç farklı döneme ait yüksek çözünürlüklü uydu görüntülerinden yararlanılmıştır. 2000 (Ikonos $1 \mathrm{~m}$ ), 2006 ve 2012 (Quickbird $0.5 \mathrm{~m}$ ) tarihlerine ait olan görüntüler, zaman içerisinde kentsel alan kullanımlarında meydana gelen değişimlerin analizini sağlayacak şekilde "Yapılaşma Alanları, Aktif Yeşil Alanlar, Diğer Yeşil Alanlar ve Diğer Alanlar" olmak üzere dört sınıf doğrultusunda sayısallaştırılmışlardır (Çizelge 1). Alan kullanım sınıfları kapsamında yer verilen "Aktif Yeşil Alan" kavramı, 14.06.2014 tarih ve 29030 sayılı Mekansal Plânlar Yapım Yönetmeliği'nde tanımlanarak yürürlüğe giren "Sosyal Açık ve Yeşil Alanlar" kavramının karşılığ1 olarak kullanılmıştır. Söz konusu yönetmeliğin ekinde "Sosyal Açık ve Yeşil Alanlar", "Çocuk bahçesi, park, botanik parkı, hayvanat bahçesi, mesire yeri, rekreasyon" olarak tanımlanmaktadır. Bu tanımlamada yer alan rekreasyon kavramının çok genel bir içeriğe sahip olması nedeniyle kentsel alan kullanımlarının sınıflandırılmasında bir belirsizlik ortaya çıkmış, bu nedenle, "Aktif Yeşil Alan" kavramının kullanılması tercih edilmiştir (Çizelge 1). Aktif yeşil alanların kapsamı, halkın rekreasyonel amaçlarla kullanımına sunulmak üzere tesis edilmiş park, çocuk bahçesi, oyun - spor alanı olarak belirlenmiş, bazı parkların piknik amaçlı kullanılmasından dolayı mesire adı altında bu alanlar da aktif yeşil alanlara dahil edilmişlerdir. Alan kullanımları sayısallaştırma işlemleri el ile ekran üzerinden ArcGIS 9.3 yazılımı yardımıla gerçekleştirilmiştir. 
Çizelge 1. Alan kullanımlarının sayısallaştırılmasında göz önüne alınan sınıflar

\begin{tabular}{ll}
\hline Sinıflar & Kapsamı \\
\hline Aktif Yeşil Alanlar & Park, çocuk bahçesi, oyun ve spor alanı, mesire yeri vb. \\
Diğer Yeşil Alanlar & Orman, ağaçlık alan, refüj, mezarlık vb. \\
Yapılaşma Alanları & Bina, asfalt ve beton yüzey vb. \\
Diğer Alanlar & Tarım alanı, çıplak alan vb. \\
\hline
\end{tabular}

\section{Değişim analizi}

2000-2012 y1lları arasında kentsel alan kullanımlarında meydana gelen değişimlerin farklı bakış açılarıyla incelenmesi ve bu değişimin yeşil alan yeterliği üzerindeki etkilerini ortaya koyabilmek amacıyla hesaplanan yüzölçümleri üç farklı analiz doğrultusunda yorumlanmıştır.

Yeşil alanların kent bütününe ve nüfusa orant: Yeşil alanlar ile yapılaşma alanlarının kent bütünü içerisindeki oranları yüzde (\%) olarak her üç yıl için incelenmiş, böylece birbirlerine oranla büyüme düzeyleri ortaya konulmuştur. Ayrıca, yine her üç yıl için kişi başına aktif yeşil alan miktarları metrekare $\left(\mathrm{m}^{2}\right)$ cinsinden hesaplanarak yıllar bazında ortaya çıkan değişimler belirlenmiştir.

Yeşil alanların parsel sayıları ve genişlikleri: Aktif yeşil alan parsellerinin sayıları ve parsel genişlikleri her yıl için hesaplanmış, böylece parsel parçalılık durumunda yıllar bazında meydana gelen değişimler incelenmiştir. Kentsel yeşil alanların yüzölçümleri üzerine gerçekleştirilen benzer araştırmalarda, park vb yeşil alanların kent dokusuna ve kullanıcılara ekolojik ve rekreasyonel yönden yeterli katkıyı sağlayabilmesi için parsellerin $2000 \mathrm{~m}^{2}$ veya daha üzerinde yüzölçüme sahip olması gerektiği belirtilmektedir (Westmacott, 1991; Anonymous, 2004). Bu çalışmada da, Kahramanmaraş kentinde bulunan aktif yeşil alanların parsel genişlikleri her yıl için ayrı ayrı gruplandırılmış ve ortaya çıkan değişimler $2000 \mathrm{~m}^{2}$ esas alınarak değerlendirilmiştir.
Yeşil alanlara ulaşılabilirlik: Kent halkının aktif yeşil alanlardan uygun koşullarda yararlanabilmesi için ideal yürüme mesafelerinde ulaşım olanağına sahip olmaları gerekliliğinden yola çıkılarak değerlendirmeler yapılmıştır. $\mathrm{Bu}$ amaçla, her bir parsel çevresinde, o parsele yürüyerek ulaşma ideal mesafesini sembolize eden tampon alanlar oluşturularak hizmet etki alanları belirlenmiştir (Herzele ve Wiedemann, 2003, GermannChiari ve Sealand, 2004). Bu çalışmada parsel çevrelerinde tampon alanlar oluşturulmasında Mekansal Plânlar Yapım Yönetmeliği'nde çocuk bahçesi, oyun alanı, açık semt spor alanı vb. için öneri olarak sunulan $500 \mathrm{~m}$ göz önüne alınmıştır. Aktif yeşil alan parselleri hizmet etki alanları her üç yıl için hesaplanmış, böylece yıllar bazında meydana gelen değişimler ortaya konulmuştur. Alan hesaplamasında yalnızca $2000 \mathrm{~m}^{2}$ ve üzerinde yüzölçümüne sahip parseller göz önüne alınmış, böylece ekolojik ve rekreasyonel yönden asgari yeterlik gösterdiği kabul edilen aktif yeşil alanların kent bütünündeki katkıları ortaya konulmaya çalışılmıştır.

\section{BULGULAR ve TARTISMA}

\section{Değișim analizi}

Kahramanmaraş kentinde 2000 ve 2012 yılları arasında alan kullanım yapısında meydana gelen değişimler incelendiğinde, araştırma alanının \% 25'ini meydana getiren 25372 da arazide alan kullanımlarının değişime uğradığı belirlenmiştir (Çizelge 2; Şekil 3).

Çizelge 2. Yıllara göre alan kullanım değişimleri

\begin{tabular}{lccrcc}
\hline & \multicolumn{2}{c}{ Yüzölçümü (da) } & \multicolumn{2}{c}{ Değişim } \\
& \multicolumn{1}{c}{2000} & 2006 & 2012 & \multicolumn{1}{c}{ da } & $\%$ \\
\hline Aktif Yeşil Alanlar & 131 & 410 & 548 & 417 & 318 \\
Diğer Yeşil Alanlar & 4417 & 4582 & 4619 & 202 & 5 \\
Yapılaşma Alanları & 16373 & 19542 & 28440 & 12067 & 74 \\
Diğer Alanlar & 82414 & 78801 & 69728 & -12686 & -15 \\
Toplam & 103335 & 103335 & 103335 & 25372 & \\
\hline
\end{tabular}

12 yıl süresince Yapılaşma Alanları \%74 oranında (12067 da) büyüme göstermiş, Diğer Alanlar'da ise 12686 da azalma ortaya çıkmıştır. Oran bakımından en büyük değişim Aktif Yeşil Alanlar'da görülmüş, bu alanlar 4 kat büyüyerek 2000 yılında 131 da olan yüzölçümü 2012 yılında 548 da'ya ulaşmıştır. Oran bakımından en düşük değişim Diğer Yeşil Alanlar'da görülmüş, bu alanlarda kaydedilen 202 da'lık artış büyük ölçüde yeni açılan kent içi yollarda tesis edilen refüjler ve kamu alanlarındaki küçük ölçekli ağaçlandırmalardan kaynaklanmıştır. Dönemler bazında incelendiğinde Aktif Yeşil Alan yüzölçümündeki en yüksek artış 2000-2006 yılları arasında meydana gelmiş, Yapılaşma Alanları ise özellikle 2006-2012 döneminde artış göstermiştir. 
Yeşil alanların kent bütününe ve nüfusa oranı

Yeşil alanların kent bütünündeki oranları incelendiğinde, Aktif Yeşil Alan oranının 12 yıl içerisinde \% 0.1 'den $\% 0.5$ 'e, Diğer Yeșil Alanlar oranının da \% 4.3’ten \% 4.5'e çıktı̆̆ı görülmektedir. Aynı dönemde Yapılaşma Alanları'nın kent bütünü içerisindeki oranı ise \% 15.8'den \% 27.5'e yükselmiştir. $\mathrm{Bu}$ durum 2000-2012 yılları arasında yapılaşma alanlarının büyük bir hızla genişlediğini, Aktif Yeşil Alanlar yüzölçümünün ise miktar bakımından artmış olmakla birlikte, araștırma alanı bütünündeki oranının düşük kaldığını göstermektedir (Çizelge 3).

Kişi başına Aktif Yeşil Alan miktarı incelendiğinde, 2000 yilında $0.4 \mathrm{~m}^{2}, 2006$ yilında $1.1 \mathrm{~m}^{2}$ ve 2012 yilında ise $1.24 \mathrm{~m}^{2}$ olarak hesaplanmıştır (Çizelge 4). Kentte 2000 ve 2012 yılları arasında toplam yüzölçümünün 4 kat büyümesine karşın kişi başına $\mathrm{m}^{2}$ değerlerinin düşük kalmasının en önemli nedeni, kent nüfusunun da hızlı bir şekilde artıyor olmasıdır. Bu veriler aynı zamanda, Kahramanmaraş kentinde kişi başına miktarın 2012 yılı itibarıyla ideal seviyeye $\left(10 \mathrm{~m}^{2} / \mathrm{kişi}\right)$ ulaşabilmesi için, mevcut bulunanlara ek olarak 3887 da daha Aktif Yeşil Alan tesis edilmesi gerektiğini ortaya koymuştur. Bununla birlikte, Aktif Yeşil Alanlara Diğer Yeşil Alanlar da dahil edilerek hesaplama yapıldığında, kişi başına düşen miktar 2012 yılı için $11.6 \mathrm{~m}^{2}$ olarak hesaplanmıştır. $\mathrm{Bu}$ durum, aktif yeşil alan yeterliğini iyileştirmeye yönelik olarak Kahramanmaraş kenti ve yakın çevresinde potansiyel yeşil alanlar bulunduğunu ortaya koyması bakımından önem taşımaktadır.

Çizelge 3. Alan kullanımlarının kent bütünü içerisindeki oranları

\begin{tabular}{llll}
\hline & 2000 & $\begin{array}{l}2006 \\
(\%)\end{array}$ & 2012 \\
\hline Aktif Yeşil Alanlar & 0.1 & 0.4 & 0.5 \\
Diğer Yeşil Alanlar & 4.3 & 4.4 & 4.5 \\
Yapılaşma Alanları & 15.8 & 18.9 & 27.5 \\
Diğer Alanlar & 79.8 & 76.3 & 67.5 \\
Toplam & 100 & 100 & 100 \\
\hline
\end{tabular}

Çizelge 4. Kişi başına aktif yeşil alan miktarı

\begin{tabular}{lrrr}
\hline & 2000 & 2006 & 2012 \\
\hline Toplam $\left(\mathrm{m}^{2}\right)$ & 131207 & 410202 & 548054 \\
Nüfus & 326198 & 371463 & 443575 \\
Kişi Başına $\left(\mathrm{m}^{2}\right)$ & 0.40 & 1.10 & 1.24 \\
\hline
\end{tabular}

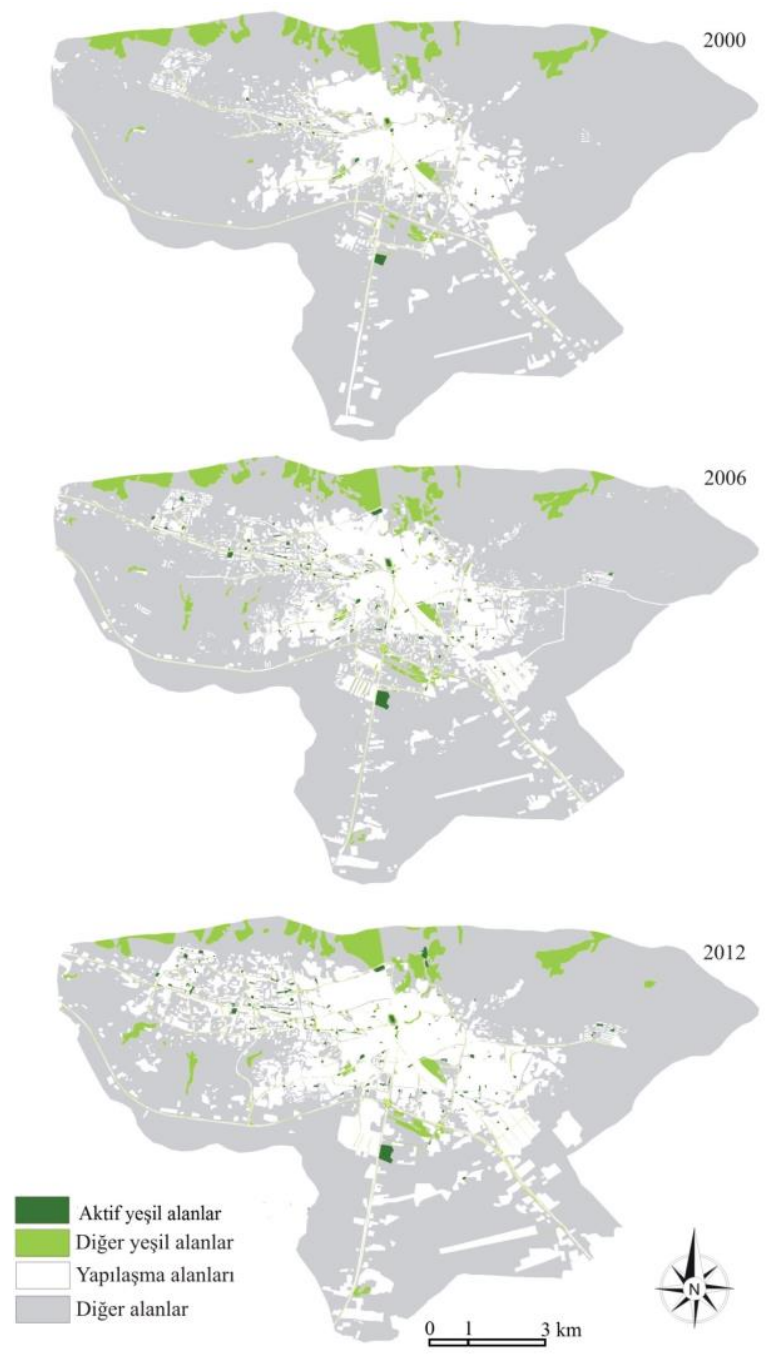

Şekil 3. Yıllara göre kentsel alan kullanımlarının dağılımları 
Yeşil alanların parsel sayıları ve genişlikleri

Araştırma alanında bulunan Aktif Yeşil Alan parsel sayıları yıllar bazında incelendiğinde, 2000 yılında 24 olan parsel sayısının yaklaşık dört kat artarak 2006 yılında 98'e ve 2012 yılında da 134'e yükseldiği görülmüştür (Çizelge 5). Bununla birlikte, park vb. alanların kent dokusuna ve kullanıcılara ekolojik ve rekreasyonel yönden yeterli katkıyı sağlayabilmesi için gerekli olan minimum $2000 \mathrm{~m}^{2}$ (2 da) yüzölçümü (Westmacott, 1991; Anonymous, 2004) göz önüne alınarak incelendiğinde, Kahramanmaraş kentinde 2000 $\mathrm{m}^{2}$ 'nin altında çok sayıda parsel olduğu belirlenmiştir. $2000 \mathrm{~m}^{2}$ 'nin altında yüzölçümüne sahip parsellerin oranı 2000 yılında \% 25 iken bu oran 2012 yılında \% 40'a yükselmiştir. Aktif Yeşil Alan parsellerinin sayı ve yüzölçümü bakımından ortaya koyduğu değerler ve bu değerlerin yıllar bazında gösterdiği değişimler, parsel sayısındaki artış nedeniyle nicelik bakımından önemli bir iyileşmenin söz konusu olduğunu, ancak parsellerin \% 40'ının ekolojik ve rekreasyonel yönden yeterli olmayan yüzölçümüne sahip olması nedeniyle nitelik yönünden benzer bir iyileşmenin sağlanamadığını ortaya koymaktadır.

Çizelge 5. Aktif yeşil alan parsellerinin yüzölçümlerine göre dağılımı

\begin{tabular}{|c|c|c|c|c|c|c|c|}
\hline \multicolumn{8}{|c|}{ Parsel Yüzölçümü (da) } \\
\hline & $\overrightarrow{\mathrm{V} I}$ & $\begin{array}{l}\stackrel{9}{1} \\
\stackrel{-}{\rightleftarrows}\end{array}$ & $\begin{array}{l}9 \\
\ddot{1} \\
1 \\
\sim\end{array}$ & $\begin{array}{l}\hat{\sigma} \\
1 \\
+\end{array}$ & $\stackrel{a}{a}$ & $\begin{array}{l}\text { VI } \\
0\end{array}$ & $\frac{\Xi}{\frac{\pi}{0}}$ \\
\hline & \multicolumn{7}{|c|}{ Adet } \\
\hline 2000 & - & 6 & 12 & 4 & 1 & 1 & 24 \\
\hline 2006 & 15 & 25 & 39 & 13 & 2 & 4 & 98 \\
\hline 2012 & 18 & 35 & 54 & 17 & 5 & 5 & 134 \\
\hline
\end{tabular}

Yeşil alanlara ulaşılabilirlik

Kahramanmaraş kentinde bulunan $2000 \mathrm{~m}^{2}$ ve üzerindeki Aktif Yeşil Alan parsellerinin çevresinde, yürüyerek ulaşma ideal mesafesini sembolize eden 500 m'lik tampon alanlar oluşturulmuş ve bu parsellerin kent bütününde ideal olarak hizmet verebildiği alan miktarları harita üzerinde belirlenebilmiştir (Şekil 4). Buna göre, 2000 yılı itibarıyla Aktif Yeşil Alan'ların hizmet etki alanı 12086 da bulunmuş, bu da araştırma alanı genelinin \% 12'sini meydana getirmiştir. Sonraki yıllarda parsel sayısının artması sonucunda Aktif Yeşil Alanlara yürüyerek ulaşma olanağında nisbi iyileşme söz konusu olmuştur. Nitekim bütün parsellerin hizmet etki alanları 2006 yılında araştırma alanı yüzölçümünün \% 25'ine (25845 da), 2012 y1lında ise \% 30'una ulaşmıştır (30876 da).
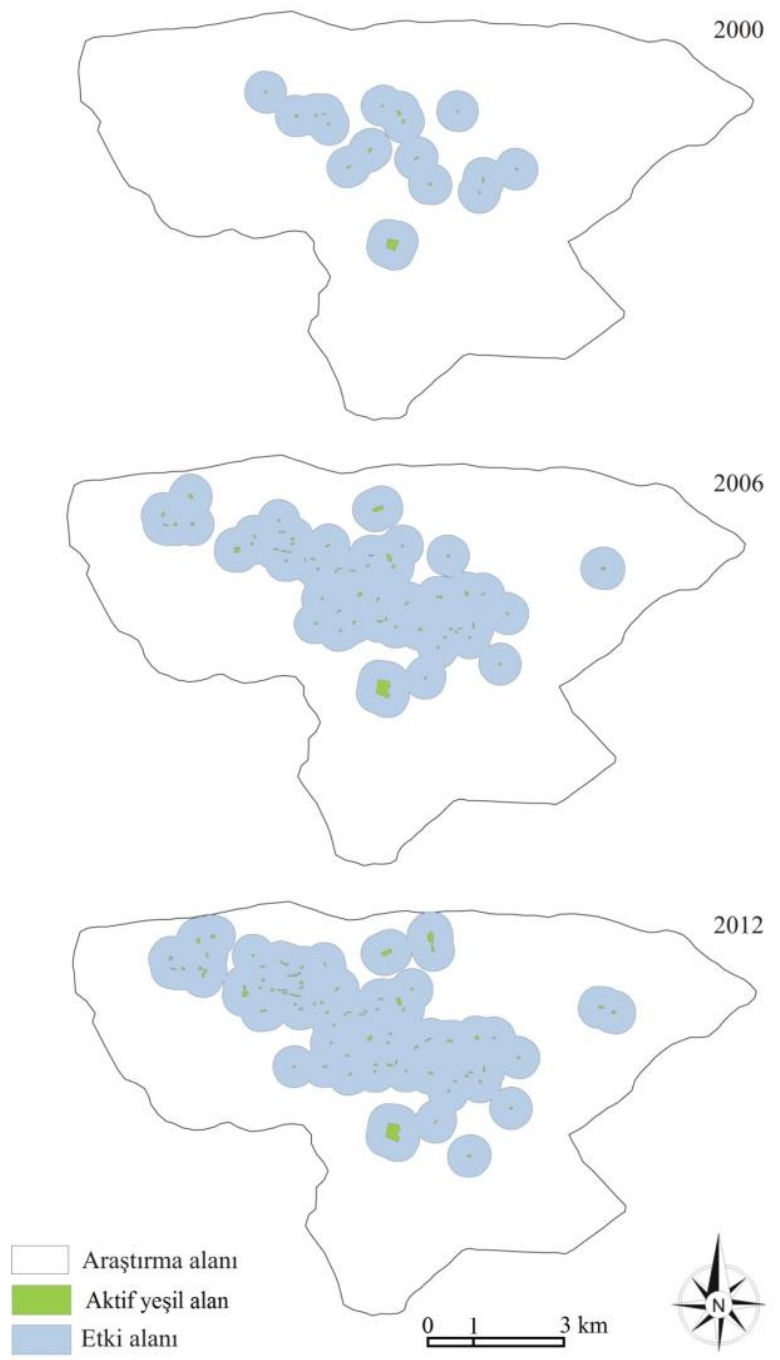

Şekil 4. Aktif yeşil alan hizmet etki alanları 


\section{SONUC ve ÖNERILER}

2013 yılı itibarı ile ülkemiz nüfusunun \%80'inin kentlerde yaşıyor olması, hızlı kentleşme ve yaşam kalitesi arasındaki ilişkinin daha etkin ve çok yönlü bakış açısı ile incelenmesi gerektiğine işaret etmektedir. Kahramanmaraş kenti için gerçekleştirilen bu çalışma ile, kent ekosisteminin ve kentsel yaşam kalitesinin iyileştirilmesinde büyük öneme sahip bulunan yeşil alanların yeterliği, yapılaşma alanları ve nüfus ile oranlanarak yıllar bazında incelenmiştir. 2000, 2006 ve 2012 yıllarına ait yüksek çözünürlüklü uydu verilerinin coğrafi bilgi sistemi ortamında yorumlanması ile elde edilen sonuçlar, Kahramanmaraş kentinde aktif yeşil alan yüzölçümünün 12 yıl içerisinde dört kat büyüdüğünü, bununla birlikte; kişi başına $\mathrm{m}^{2}$ miktarı, yürüyerek ulaşma olanağı, ortalama parsel genişliği ve araştırma alanı bütünü içerisindeki oranı bakımından incelendiğinde beklenen yeterliğin sergilenemediği anlaşılmıştır. Kahramanmaraş kentinde aktif yeşil alanların yüzölçümü bakımdan önemli bir artışa karşın kent yaşantısına olan katkılarının düşük düzeyde kalmasının en önemli nedeni, son y1llarda kent nüfusunda görülen hızlı artıştır. Yani, çok miktarda yeşil alan tesis ediliyor olması önemli bir gelişme olarak kabul edilmekle birlikte, kent nüfusunun daha hızlı bir şekilde artıyor olması aktif yeşil alanların istenilen katkıyı sağlayamamasına neden olmaktadır.

Kahramanmaraş kentinde aktif yeşil alanları nitelik bakımından iyileştirmek için en geçerli yaklaşım; kentte kişi başına $10 \mathrm{~m}^{2}$ yeterliğini sağlayacak miktarda yeşil alan tesis etmek, parselleri kent bütününde homojen dağılım sergileyecek şekilde konumlandırmak ve 2000 $\mathrm{m}^{2}$ nin altında yüzölçüme sahip parsel oluşturmamaktır. Bununla birlikte, kentte aktif yeşil alan yeterliğinin ideal ve kalıcı bir şekilde iyileştirilebilmesi için yukarıda bahsi edilen planlama anlayışının nazım ve uygulama imar planlarına da yansitılması gerekmektedir.

Kentte genelinde oluşturulacak bir yeşil alan sistemi, yeşil alanların kentsel yaşam kalitesine etkinliğinin artırılmasında önem taşımaktadır. Bu bağlamda, yeşil alanların potansiyelleri göz önüne alınarak planlanan ekolojik bağlantı ve kuşak alanları içeren sürdürülebilir bir kentsel yeşil alan sisteminin, kentsel gelişmeye olumlu etkileri olacağı göz ardı edilmemelidir (Özcan, 2006). Bölgedeki kentleşme tipi, mevcut ve planlanan açık ve yeşil alan kullanımları, çevre arazi kullanımları, yeşil alanların etki alanları, nüfusun yapısı ve gelişimi Kahramanmaraş kenti veya diğer benzer örneklere yönelik yeşil alan sistemi planlanmasında belirleyici unsurlardır (Manavoğlu, 2007).

Ekolojik ağlar ve yeşil yollar gibi bağlantılı sistemler, yeşil alanların planlanmasında, içinde bulunduğumuz ekolojik dönem olarak adlandırılabilecek süreçte, gelişmiş ülkelerin planlama pratiklerinde kendine yer edinmekte olan bilimsel bulgular ve tasarım uygulamalarının ekolojik ortak paydada buluştuğu sürdürülebilirlik amacına hizmet eden yeni planlama konseptleridir (Yaman ve Doygun, 2014).
Kahramanmaraş kenti, coğrafi konumu ve hidrografik zenginliğiyle yüksek bir doğal potansiyel barındırmakla birlikte; fonksiyonel, bağlantılı, bütüncül bir yeşil alan sistemi kentin söz konusu potansiyelinin sürdürülebilir şekilde geliştirilmesini sağlayacaktır. Aynı zamanda, yoğun kentleşme süreci yaşayan kentlerin bir yeşil alan sistemi dahilinde planlanmasının, kentsel gelişimi yönlendirme anlamında da olumlu katkıları olacağı muhakkaktır.

\section{TEŞEKKÜR}

$\mathrm{Bu}$ çalışma, Kahramanmaraş Sütçü İmam Üniversitesi tarafindan desteklenen 2012/4-10M nolu araştırma projesi kapsamında gerçekleştirilmiştir.

\section{KAYNAKLAR}

Altunkasa, M. F., Uslu, C. 2004. The effects of urban green spaces on house prices in the upper northwest urban development area of Adana (Turkey). Tur. J. of Agriculture and Forestry 28: 203-209.

Anonymous, 2004. Making greener cities: a practical guide, Development of urban green spaces to improve the quality of life in cities and urban regions. Research Project, UZF Center for Environmental Research (Unpublished), Leipzig.

Attwell, K. 2000. Urban land resource and urban planting-case studies from Denmark. Landscape and Urban Planning, 52: 145-163

Doygun, H. İlter, A. A. 2007. Kahramanmaraş kentinde mevcut ve öngörülen aktif yeşil alan yeterliğinin incelenmesi. Ekoloji, 17(65): 21-27.

Doygun, H., İlçim, A., Atmaca, M., Oğuz, H. 2010. Kahramanmaraş kentinde biyotopların haritalanması. Araştırma projesi. Türkiye Bilimsel ve Teknolojik Araştırma Kurumu (Basılmamış), Kahramanmaraş.

Eşbah, H. 2006. Aydın'da kent parklarının bazı ekolojik kalite kriterleri yönünden irdelenmesi. Ekoloji, 15(58): 42-48.

Germann-Chiari, C., Sealand, K. 2004. Are urban green spaces optimally distributed to act as places for social integration? Results of a geographical information system (GIS) approach for urban forestry research. Forest Policy and Economics, 6: 3-13

Grahn, P., Stigsdotter, U. A. 2003. Landscape planning and stress. Urban Forestry and Urban Greening, 2: 1-18.

Gül, A., Küçük, V. 2001. Kentsel açık-yeşil alanlar ve Isparta kenti örneğinde irdelenmesi. SDÜ Orman Fakültesi Dergisi, 2: 27-48.

Herzele, A. V. Wiedemann, T. 2003. A monitoring tool for the provision of accesible and attractive urban green spaces. Landscape and Urban Planning, 63: 109-126.

Li, F., Wang, R., Paulussen, J., Liu, X. 2005. Comprehensive concept planning of urban greening based on ecological principles: a case study in Beijing, China. Landscape and Urban Planning, 72: 325-336. 
Littke, H. 2015. Planning the green walkable city: conceptualizing values and conflicts for urban green space strategies in Stockholm. Sustainability, 7: 11306-11320

Manavoğlu, E., Ortaçeşme, V., 2007. Konyaaltı Kentsel Alanında Bir Yeșil Alan Sistem Önerisi Geliştirilmesi. Akdeniz Üniversitesi Ziraat Fakültesi Dergisi 20(2): 261-271.

Manlun, Y. 2003. Suitability analysis of urban green space system based on GIS. MSc Thesis, International Institute for Geo-Information Science and Earth Observation (Unpublished), The Netherlands.

Özcan, K., 2006. Sürdürülebilir Kentsel Gelişmede Açık-Yeşil Alanların Rolü "Kırıkkale, Türkiye Örneği. Ekoloji 15, 60: 37- 45.

Ridder, D. K., Adamec, V., Banuelos, A., Bruse, M., Bürger, M., Damsgaard, O., Dufek, J., Hirsch, J., Lefebre, F., Perez, Lacorzana, J. M., Thierry, A., Weber, C. 2004. An integrated methodology to assess the benefits of urban green spaces. Science and the Total Environment, 334-335: 489-497 .

Shin, D. H., Lee, K. S. 2005. Use of remote sensing and geographical information system to estimate green space temperature change as a result of urban expansion. Landscape and Ecological Engineering, 1: 169-176.

Solecki, W. D., Rosenzweig, C., Parshall, L., Pope, G., Clark, M., Cox, J., Wiencke, M. 2005. Mitigation of the heat island effect in urban New Jersey. Environmental Hazards, 6: 39-49.
Tratsaert, K. 1998. Stads(v)lucht maakt vrij: analyse van de verhuisstromen en een bevraging van de verhuismotieven en woonwensen van jonge gezinnen in het Leuvense Hoger. Research project, Instituut voor de Arbeid Katholieke Universiteit (Unpublished), Leuven.

Uy, P. D., Nakagoshi, N. 2008. Application of land suitability analysis and landscape ecology to urban greenscape planning in Hanoi, Vietnam. Urban Forestry and Urban Greening, 7: 25-40.

Ülger, F. N., Önder, S. 2006. Kayseri kenti açık-yeşil alanlarının nitelik ve nicelik açısından incelenmesi. Selçuk Üniversitesi Ziraat Fakültesi Dergisi, 20(38): 108-118.

Westmacott, R. 1991. Scale economics: ecological theory and planning practice in urban landscapes. Landscape and Urban Planning, 21: 21-29.

Wolch, J. R., Byrne, J., Newell, J. P. 2014. Urban green space, public health, and environmental justice: The challenge of making cities 'just green enough'. Landscape and Urban Planning, 125: 234-244.

Yaman, G., Doygun, H., 2014. Yeşil Alanların Kent Ekosistemine Katkılarının Kahramanmaraş Kenti Örneğinde İncelenmesi. II. Ulusal Akdeniz Orman ve Çevre Sempozyumu, 22-24 Ekim 2014, 252-260.

Yıldızc1, A. C. 1982. Kentsel yeşil alan planlaması ve İstanbul örneği. Doçentlik tezi (Basılmamış). İTÜ Mimarlık Fakültesi İstanbul. 